\title{
Peppermint Oil
}

National Cancer Institute

\section{Source}

National Cancer Institute. Peppermint Oil. NCI Thesaurus. Code C84045.

The essential oil extracted from the leaves of Mentha x piperita. Peppermint oil is used for its aromatic properties and as a flavoring and to treat illnesses of the digestive and respiratory system as well as pain. 